\title{
analysis
}

\section{Tracking toxins}

\author{
Biomonitoring outshines theindirect assessment of exposure in determining which pollutants enter the \\ body, and whether they causediseaseor disability
}

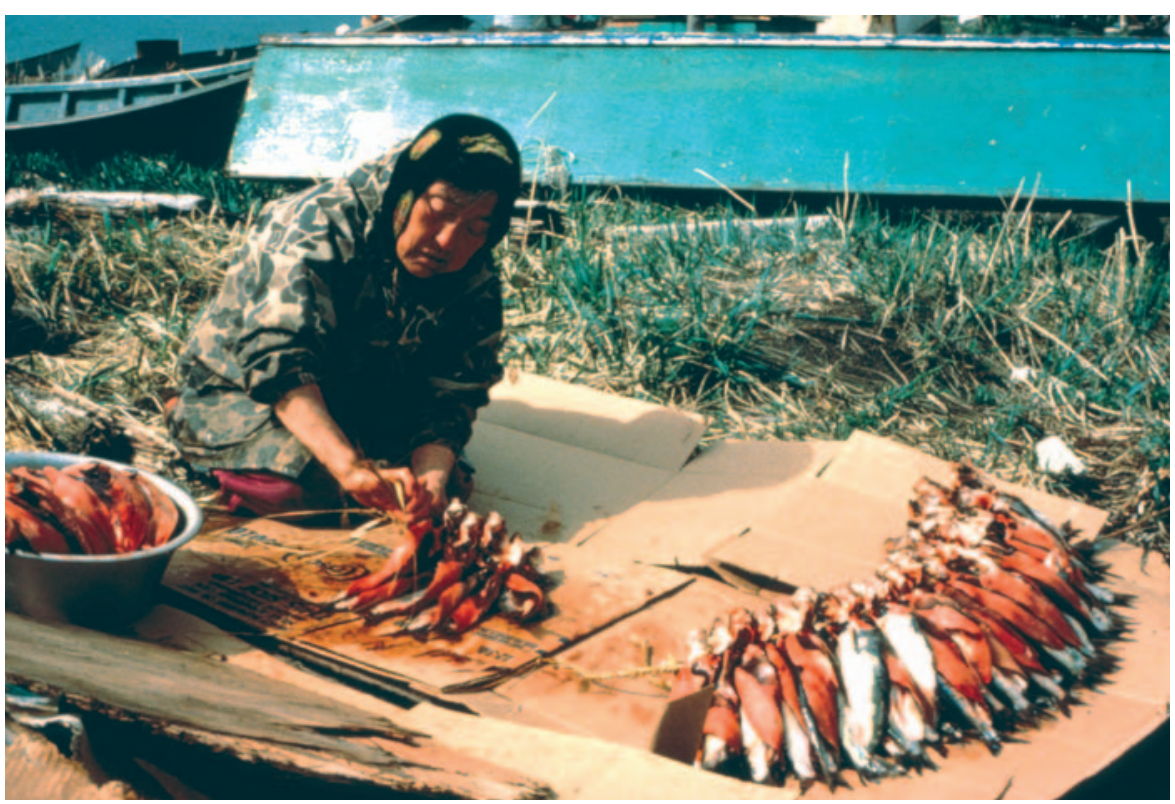

Fig1 |A NativeAlaskan woman prepares fish for her family. Used with permission from theAlaska Division of Community and Business Development.

$S^{n}$ hould this woman feed these fish to her family (Fig 1)? For her and her children, this is a serious question. High in the Arctic where they live, airborne pollutants from industrial and agricultural activities far to the south have become a serious environmental and human health problem. When people eat animals from the top of the food chain, such as predatory birds, fish and mammals, they also consume highly concentrated contaminants, such as methylmercury and persistent organic pollutants (POPs), which include polychlorinated biphenyls (PCBs). These toxins can harm the developing nervous system of a fetus or child, and some POPs may also affect the immune and endocrine systems.
Eight Arctic countries-Canada, Denmark (Greenland), Finland, Iceland, Norway, Russia, Sweden and the USA (Alaska)-face this dilemma: Should they allow their people to continue eating traditional seafoods, which are rich in omega-3 fatty acids, vitamins, minerals and protein, or advise them to limit their intake? The European Food Safety Authority (EFSA; Parma, Italy) suggests that children and women of childbearing age should eat a variety of fish species, but only small amounts of swordfish and tuna (EFSA, 2004). The US Environmental Protection Agency (EPA) and Food and Drug Administration (FDA) go even further and advise women of childbearing age, pregnant or breastfeeding women, and young children to eat fish only once or twice a week, depending on the species. This baffles Native Alaskans, many of whom live where there is little else to eat- unless they adopt a Western diet. And if they do, they may become obese and develop diabetes or heart disease- health problems once unknown in the Arctic, but now becoming common (Van Oostdam et al, 1999; Arnold et al, 2005).

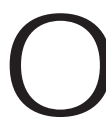

ne way to address this dilemma is to use biomonitoring-the measurement of chemical contaminants or their metabolites in human hair, blood, urine and other tissues or fluids (Table 1). This gives scientists and health experts a better sense of which chemicals actually enter the body - from breathing the air, from eating and drinking, and from absorbing chemicals across the skin-and to study whether they cause disease or disability. "Exposure occurs when a chemical comes in contact with a person," explained Larry Needham from the US Centers for Disease Control and Prevention (CDC; Atlanta, GA, USA). "A portion of that exposure dose is absorbed into the body, where it's distributed, metabolized and excreted. A portion reaches the target site and may be biologically active." On the basis of such studies, health experts can make better recommendations for people such as the native inhabitants of the Arctic, with respect to how much and which foods they should eat.

Furthermore, when used in population surveys, biomonitoring yields important data on the pollution exposure of whole populations and can inform policies aimed at reducing sources of contaminants and preventing exposure. The $1998 \mathrm{German}$ Environmental Survey, for instance, measured metals and metabolites of organic chemicals in urine, and reported that East German residents had 
Table 1 | Examples of biomarkers measured in human samples

\begin{tabular}{ll}
\hline Tissuesample & Biomarker \\
\hline Hair & Arsenic, methylmercury \\
\hline Blood & Methylmercury, cadmium, lead \\
\hline Blood serum & $\begin{array}{l}\text { PCBs(polychlorinated biphenyls), PBDEs (polybrominated diphenyl ethers), } \\
\text { dioxins, furans, persistent organochlorine pesticides such as DDT } \\
\text { (1,1,1-trichloro-2, 2-bis(p-chlorophenyl)ethane), DDE (1,1-dichloro-2, 2-bis } \\
\text { (p-chlorophenyl)ethylene) }\end{array}$
\end{tabular}

Urine Organophosphate pesticides, non-persistent pesticides such as atrazine, malathion, 2,4-D (2,4-dichlorophenoxyacetic acid), parathion, alachlor; many metals, such as inorganic mercury, cadmium, cobalt, lead, uranium
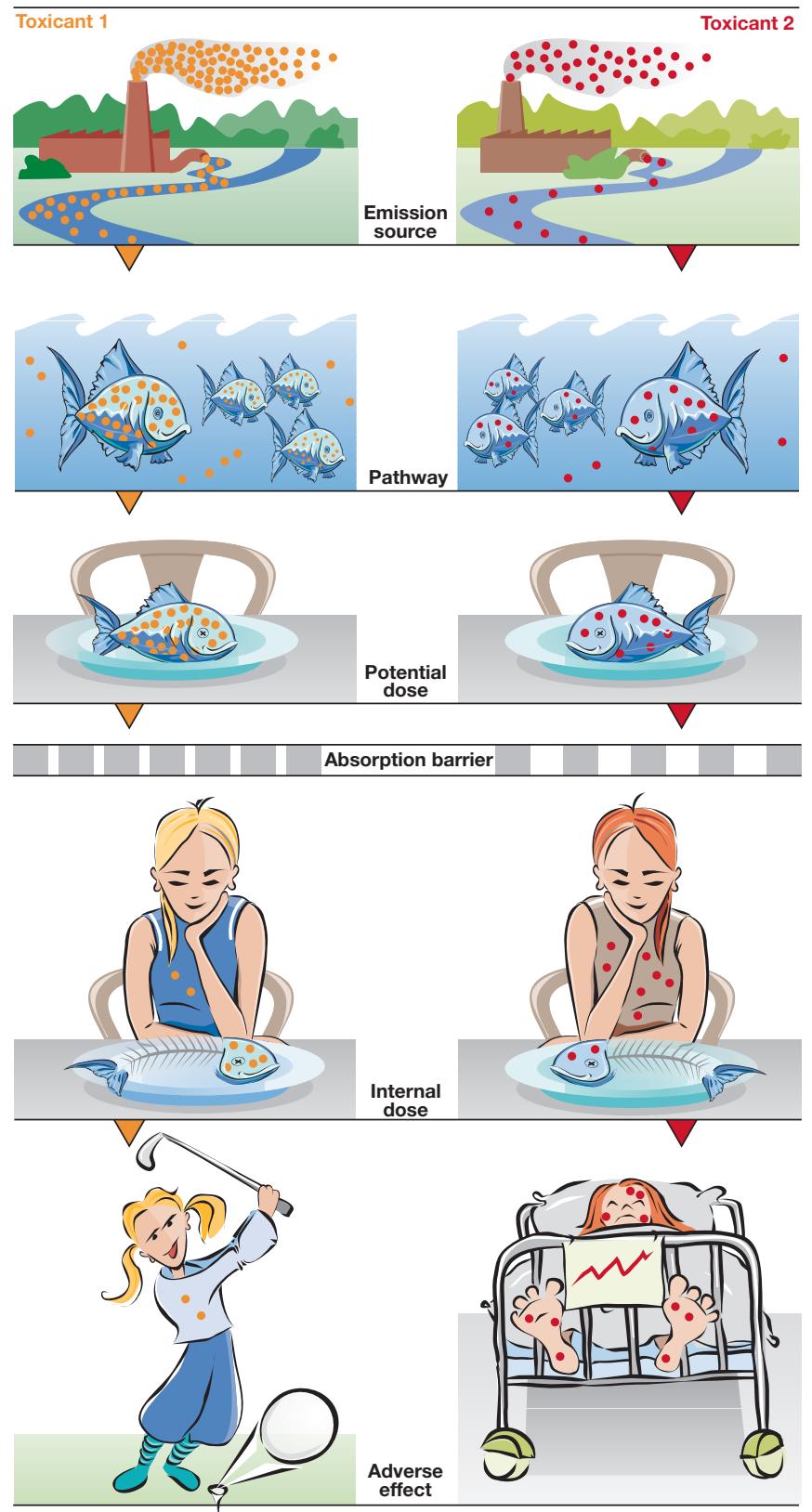

Fig2 | Without biomonitoring, researchers must estimatethejourney of a chemical through these steps to its absorption into the body and possible health effects. With biomonitoring, researchers can more accurately measure how much chemical was absorbed, making it easier to study relationships between toxic exposures and health effects. Adapted with permission from Sexton etal, 2004. lower urinary concentrations of-thus, less exposure to-cadmium, mercury and polycyclic aromatic hydrocarbons than in 1990-1992, shortly after reunification (Becker et al, 2003). Reduced emissions in the East and lower food contamination may account for the decline. Nationwide, pentachlorophenol (PCP) concentrations dropped sharply after 1990, following a ban on PCP production and products.

Until the methods and instruments for biomonitoring became widely available and affordable, scientists had to rely on indirect exposure assessment as the only tool to assess the levels of toxic compounds in humans (Fig 2). Long considered the Achilles heel of epidemiology, indirect exposure assessment relies on questionnaires, interviews, environmental measurements, models and exposure scenarios (Pirkle et al, 1995a; Sexton et al, 1995; Needham \& Sexton, 2000). For example, in an exposure scenario, researchers analyse the path of a chemical from its source- such as a smokestack or a production plant-through the air and water into soil, foods and people. They then use these data in models, calculations, assumptions and inferences to estimate exposure and internal doses in exposed people. Because the data are often scarce and the assumptions and inferences are manifold, scientific uncertainty is accordingly huge.

nstead, measuring concentrations of toxicants or their metabolites in human samples allows researchers to determine the internal dose directly, which is a vast improvement for public health policies. "Biomonitoring is the gold standard," Needham explained, because it enables researchers to assess what is actually absorbed by the body. But it still has its drawbacks. Although biomonitoring provides reliable data for persistent chemicals, such as PO Ps and heavy metals, it is less suitable for measuring exposure to non-persistent chemicals, such as volatile organic compounds (VOCs) or modern pesticides, which are quickly absorbed, metabolized and eliminated through the breath or urine. "For chemicals with short half-lives," said Needham, "you get a snapshot in time, which may not yield information about what really got into the body." A brief peak exposure may thus go undetected or underreported.

Researchers also need to know the physical properties of a chemical and how it is metabolized in the body to determine where and how to look for it in biomonitoring 
assays, and to assess the time lapse between exposure and measurement (Pirkle et al, 1995b; Needham \& Sexton, 2000). Fatsoluble chemicals, for instance, can be measured in blood samples, because these chemicals equilibrate between fat tissue and blood serum (Teass et al, 1994; Pirkle et al, 1995b; Needham \& Sexton, 2000). O wing to their long half-lives in fat, lipid-soluble compounds also allow exposure to be tracked over a duration of years (Fig 3). Similarly, methylmercury-a common pollutant-concentrates in the brain, kidneys and liver, and is measured in whole blood and hair (Van Oostdam et al, 1999). Conversely, many non-persistent chemicals and heavy metals are metabolized rapidly to water-soluble compounds and excreted in urine (N eedham \& Sexton, 2000). Their urinary concentrations peak within 24 hours after exposure and diminish rapidly within days (Fig 4), so chemists need to take samples shortly after exposure. VOCs diminish even faster-they can be exhaled within an hour-whereas VOCs that bind to haemoglobin can be traced for up to 120 days, the lifespan of a red blood cell.

Human genetic and physiological differences add another layer of complexity to reliable measurements (Teass et al, 1994). For example, some people excrete aniline, a benzene derivative used to make dyes and pharmaceuticals, as free amine, whereas others excrete it as an aniline-acetyl compound. By contrast, when different chemicals metabolize to the same compound, it can be difficult to identify a specific exposure. Furthermore, ethanol use can also confound analysis, as it is metabolized through three metabolic pathways, which also process other organic chemicals.

$\mathrm{D}$ espite the need for careful interpretation, biomonitoring outshines indirect exposure assessment and has already shown some public health policies to be misguided (sidebar). When unleaded gasoline was introduced in the USA in 1970-because leaded gasoline interferes with catalytic converters designed to reduce air pollution-a health model predicted that its effect on lead concentrations in the blood of US residents would be minor. But as unleaded gasoline replaced lead-containing gasoline, biomonitoring revealed dramatic declines in the lead levels found in blood (Fig 5; Sexton et al, 2004). When the CDC first identified this trend, it helped the agency's researchers persuade

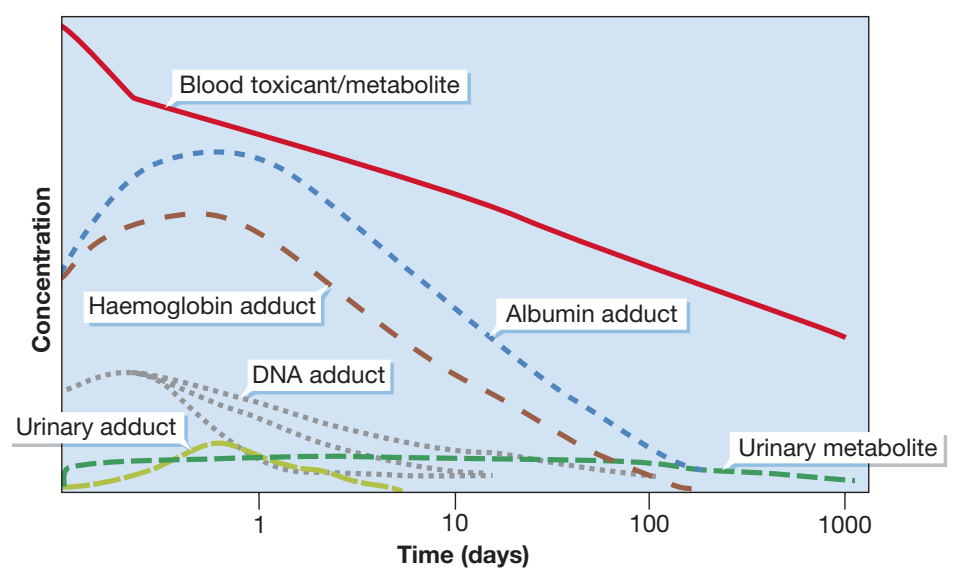

Fig 3 | Persistent toxicants aretypically fat-solubleor bind to proteins in the cell. Fat-solublechemicals accumulate in fat, equilibratewith blood serum and decline slowly over months and years. Other persistent chemicals, such as methylmercury, bind to proteins and are best measured in wholeblood. A small percentage of the dose may be metabolized into a water-soluble form that can be excreted in urine. Reprinted with permission from Needham \& Sexton, 2000.

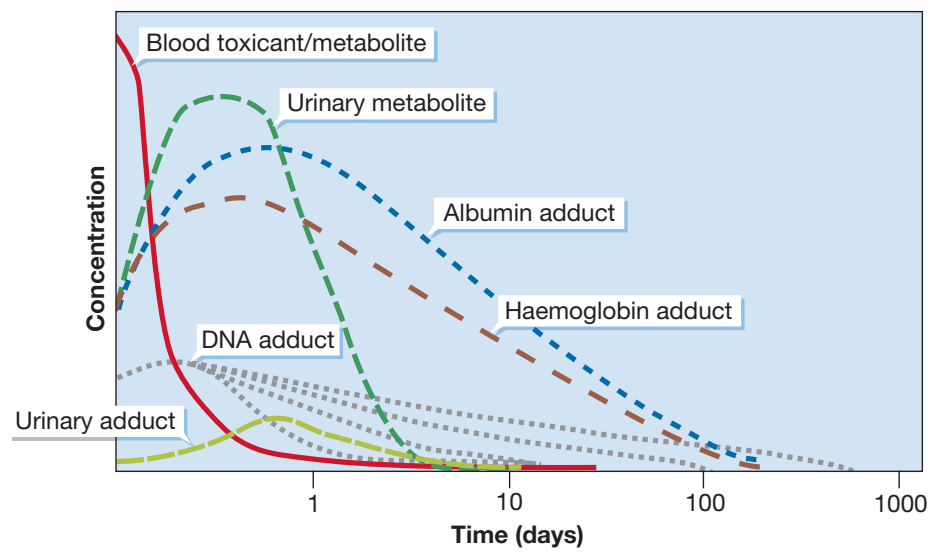

Fig4 | Non-persistent toxicants movequickly out of theblood as they are metabolized to water-soluble compounds that can be excreted in urine. Somechemicals or metabolites may bind to proteins or to DNA and persist in the body for a longer period of time- days or even months. Reprinted with permission from Needham \& Sexton, 2000.

the EPA to hasten the removal of lead from gasoline. Today, lead levels in most U S residents are around $2 \mu \mathrm{g} / \mathrm{l}$ of blood, which is an $87 \%$ decrease from the approximately 16 $\mu \mathrm{g} / \mathrm{l}$ in 1977-a level well above current definitions of lead poisoning.

In another study involving Canadian children whose parents used herbicides on their farms, biomonitoring demonstrated that questionnaire data were unreliable predictors of the children's exposure (Arbuckle et al, 2004). It showed that $30 \%$ of the children had detectable herbicide residues in their urine, including those who had been off the farm on the day the pesticides were

\section{USESOF BIOMONITORING IN PUBLIC HEALTH RESEARCH}

-M easure exposure in the general population to develop referencevalues

- Obtain internal dose measurements that integrate exposurefrom all exposure routes - dentify or study subpopulations at higher risk - dentify priority exposures

-Recognizetimetrendsin exposure

- Correlateinternal dosemeasures with external exposure measurements and estimates -Examine causal relationships between exposure and health risks

-Evaluate exposure prevention and public health policies 


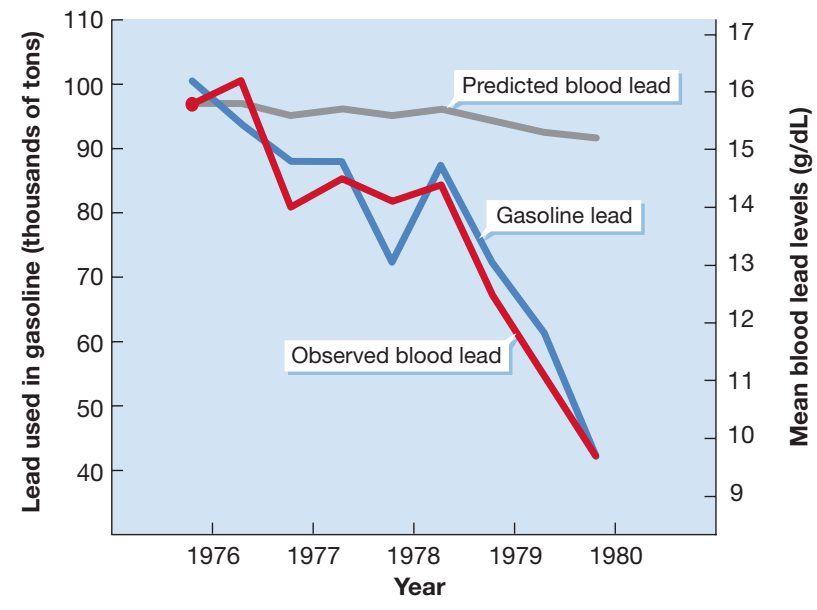

Fig5 | In the 1970s, as unleaded gasolinereplaced lead-containing gasolinein the USA, theUSCenters for Disease Control and Prevention used biomonitoring to measure levels of lead in the blood of US residents. Unexpectedly, biomonitoring showed that blood lead levels fell sharply as the use of leaded gasoline declined. However, environmental modelling had predicted little, if any, declinein blood lead concentrations as a result of a switch to unleaded gasoline. Figureadapted with permission from theUS Centers for Disease Control and Prevention.

mixed or applied. Parents of children with higher urinary herbicide residues were more likely to have higher pesticide residue concentrations in their own urine, suggesting that they may have spilled herbicides outdoors or carried contamination indoors. "Questionnaires can mislead because people don't always remember. With biomonitoring, you can validate exposure," commented Ken Sexton, Professor of Environmental and Occupational Health at the University of Texas (Brownsville, TX, USA). "Many researchers try to build a biomonitoring component into their fieldwork to double-check their other methods."

$\mathrm{B}$ iomonitoring is now being used by the Arctic Monitoring and Assessment Programme (AMAP), a subgroup of the intergovernmental Arctic Council, which advises the eight Arctic countries about the environmental and health threats of chemical contaminants. Chemicals, such as PO Ps and mercury, reach the Arctic through the air and settle on land and water. During the brief summer, microorganisms absorb PO Ps and mercury and transform mercury into methylmercury. This neurotoxic compound enters the food chain when it is taken up by algae and protozoans, which are eaten by small fish. As predator fish eat smaller fish, methylmercury accumulates in their bodies. Some predators, such as polar bears or gulls, suffer immunological, behavioural or reproductive problems; some people who have been highly exposed to methylmercury and PCBs in whale meat have shown subtle neurobehavioural effects. And although levels of PCBs are slowly declining, others, such as polybrominated diphenyl ethers (PBDEs) used in fire retardants, are rising (Ikonomou et al, 2002). Public health officials now use biomonitoring to get a better picture of the actual levels of these toxins in humans in order to balance the positive aspects of traditional diet and breastfeeding against the risks of PO Ps and mercury in fish, whale and seal that many circumpolar people eat.

\section{... some peoplewho have been highly exposed to methylmercury and PCBs in whale meat have shown subtle neurobehavioural effects}

"In Alaska, many communities have no access to other sources of food, so if you advise them to avoid traditional foods, you undermine their culture, their environment, and their health," commented John Middaugh from the Alaska Division of Public Health (ADPH). Even in Greenland, where methylmercury levels in seafoods are higher than in Alaska, local health officials now advise communities to continue to eat traditional foods, rather than switching to a Western diet with its concomitant health problems. "The biggest objection we have to the US FDA and EPA recommendations for limited fish consumption is that they don't consider the benefits of eating fish," said Scott Arnold from the ADPH. "Biomonitoring allows you not only to look at actual exposures, but to weigh benefits against risks."

ADPH has begun biomonitoring methylmercury exposure in pregnant Alaskan women and some women of childbearing age (Arnold et al, 2005). Eventually, the ADPH hopes to include all women of childbearing age and to look for more chemicals, including PCBs, pesticides and heavy metals. Early findings indicate that most pregnant women had hair mercury levels well below the World Health Organization's 'no observed effect level' (NOEL), which denotes the greatest amount of a substance that causes no detectable effect (Arnold et al, 2005). These findings were consistent with low blood mercury levels found in new mothers in the Alaskan villages of Bethel and Barrow, which further supports the view that limiting or abandoning traditional seafoods is not necessary everywhere.

\section{... local health officials now advise communities to continue to eat traditional foods, rather than switching to a Western diet with its concomitant health problems}

"Why not measure methylmercury in subpopulations and tailor our recommendations to a community's real options?" asked Middaugh. Some parts of the Arctic are cleaner than others, he observed, and some species contain much lower pollutant concentrations than others. If one fish or mammal species has high mercury and PCB levels, people can avoid it and switch to other species. The FDA has accepted the argument that dietary recommendations should reflect local conditions, which clearly shows that biomonitoring data can lead to better public policies.

$\mathrm{N}$ evertheless, biomonitoring has its downsides: it is costly. Laboratory expertise, instruments, reagents, standards and sample collections are expensive. Also, biomonitoring cannot identify the source of exposure-that requires environmental investigation. And it does not, by itself, prove that a particular 
chemical causes a particular disease. Furthermore, to ensure that laboratories produce reliable results, common standards and independent quality assessments are required. The European Union (EU) is therefore funding efforts to harmonize biological monitoring practices throughout the EU. Being wrong can be costly and carries serious risks for individuals and society.

What biomonitoring does yield is a far more accurate estimate of human exposure than do indirect methods. Furthermore, better knowledge of the distribution and metabolism of toxic chemicals in the human body, coupled with improved tools to make more accurate measurements, will further refine the technology. The next step in improving biomonitoring is to identify biological markers that would allow researchers to determine the effects of the interactions of chemicals in specific target organs or cells. "Eventually, we will be able to link exposures with early biological markers of effects," said Sexton.

\section{REFERENCES}

Arbuckle TE, Cole DC, Ritter L, Ripley BD (2004)

Farm children's exposure to herbicides: comparison of biomonitoring and questionnaire data. Epidemiology 15: 187-194

Arnold SM, Lynn TV, Verbrugge LA, M iddaugh JP (2005) H uman biomonitoring to optimize fish consumption advice: reducing uncertainty when evaluating benefits and risks. Am J Public Health 95: 393-397

Becker K, Schultz C, Kaus S, Seiwert M, Seifert B (2003) German Environmental Survey 1998 (GerES III): environmental pollutants in the urine of the German population. Int J H yg Environ $\mathrm{H}$ ealth 206: 15-24

EFSA (2004) EFSA provides risk assessment on mercury in fish: precautionary advice given to vulnerable groups. Press release, $18 \mathrm{Mar}$, www.efsa.eu.int/press_room/press_release/ 258_en.html

Ikonomou M G, Rayne S, Addison RF (2002) Exponential increases of the brominated flame retardants, polybrominated diphenyl ethers, in the Canadian Arctic from 1981 to 2000. Environ Sci Technol 36: 1886-1892

N eedham LL, Sexton K (2000) Assessing children's exposure to hazardous environmental chemicals: an overview of selected research challenges and complexities. J Expo Anal Environ Epidemiol 10: 611-629

Pirkle JL, Sampson EJ, N eedham LL, Patterson D G, Ashley DL (1995a) U sing biological monitoring to assess human exposure to priority toxicants. Environ H ealth Perspect 103: 45-48

Pirkle JL, N eedham LL, Sexton K (1995b) Improving exposure assessment by monitoring human tissues for toxic chemicals. J Expo Anal Environ Epidemiol 5: 405-424

Sexton K, Callahan MA, Bryan EF (1995) Estimating exposure and dose to characterize health risks: the role of human tissue monitoring in exposure assessment. Environ H ealth Perspect 103: 13-29

Sexton K, N eedham LL, Pirkle JL (2004) Human biomonitoring of environmental chemicals. Am Sci 92: 38-45

Teass AW, Biagini RE, DeBord DG, Hull RD (1994) Chapter F: Application of Biological M onitoring $\mathrm{M}$ ethods. In Eller PM, Cassinelli ME (eds), NIOSH Manual of Analytical Methods,

\begin{abstract}
4th edn, pp 52-62. Cincinnati, OH, USA: US Department of Health and Human Services. www.cdc.gov/niosh/nmam

Van O ostdam J et al (1999) Human health implications of environmental contaminants in Arctic Canada: a review. Sci Total Environ 230: $1-82$
\end{abstract}

\section{BarbaraScottMurdodk}

doi:10.1038/sj.embor.7400493

\section{A bloodless revolution}

\section{A growing interest in artificial blood substitutes has resulted in new products that could soon improvetransfusion medicine}

B lood transfusion was once regarded as a safe and effective practice to save a patient's life after massive blood loss. But the AIDS epidemic and concerns that donated blood could be contaminated with HIV and other infectious agents, such as the hepatitis $\mathrm{C}$ virus, shattered public confidence in blood transfusions. This only added to already existing supply problems. In the USA alone, about 4 million patients require some $10-12$ million blood units each year. About two-thirds of these are used to replace blood loss after trauma and surgery, and the remainder is used in chronic blood loss, cancer and anaemia. Because the demand for blood products continues to increase due to more sophisticated surgical procedures and the expanded health needs of an ageing population, there are often seasonal and regional shortages. The increasing demand and the loss of public faith in transfusion safety has revitalized the search for artificial blood substitutes. After many failed attempts, researchers in academia and industry are now ready to test the first promising products in laboratory and clinical trials. However, replacing our lifeblood is not as easy at it seems. "Development of an effective and safe oxygen carrier to be used instead of blood transfusion is an extreme challenge," said Robert Winslow, founder of Sangart (San Diego, CA, USA), a company that develops blood substitutes.

Although the idea of using a blood substitute in transfusions was first advanced in the seventeenth century by the British scientist Sir Christopher W ren, real efforts to develop such a product only began in the early 1930s. W illiam Amberson and colleagues at the State College of Medicine in Memphis (TN, USA) showed that bovine haemolysates could transport oxygen in mammals (Amberson et al, 1933), and later found that human haemolysates had the same potential when infused in patients (Amberson et al, 1949). Since then, the development of transfusion medicine has received much of its impetus from the military-not surprising, given that haemorrhage is the leading cause of death on the battlefield. In the 1960s, during the Vietnam War, the US Army began to collaborate with several private biomedical companies and supported research on blood substitutes based on different approaches.

Wartime experience guided developers in delineating the ideal properties of an oxygen carrier for military use: universal compatibility, and thus no time-consuming testing for blood type; no transmittable pathogens or allergens; long-term storage capability, preferably under non-refrigerated conditions; safety and non-toxicity; and superior oxygen delivery capability, resulting in oxygenation of peripheral tissues even after massive blood loss. Intuitively, this describes applications that go far beyond wounded soldiers, ranging from immediate treatment of patients in haemorrhagic shock after traumatic injuries, to relieving shortages and avoiding contaminated supplies, to assuring intervention even when religious objections or rare blood groups prevent normal blood transfusion. Additional uses can be envisaged in a variety of diseases with 